\title{
Treatment of Adult Spinal Deformity with Sagittal Imbalance Using Oblique Lumbar Interbody Fusion: Can We Predict How Much Lordosis Correction Is Possible?
}

\author{
Whoan Jeang Kim, Jae Won Lee, Kun Young Park, Shann Haw Chang, Dae Geon Song, Won Sik Choy \\ Department of Orthopedic Surgery, Eulji University Hospital, Daejeon, Korea
}

\section{Study Design: Prospective, single-center study.}

Purpose: The current trend of operative treatment for adult spinal deformity (ASD) is combined anterior-posterior staged surgery. When anterior surgery was first performed, oblique lumbar interbody fusion (OLIF) was employed; this method became increasing popular. This study aimed to determine the lordosis correction that can be achieved using OLIF and assess whether we can preoperatively predict the lordosis correction angle achieved using OLIF.

Overview of Literature: Many previous studies on OLIF have shown improved clinical and radiologic outcomes. With the increase in the popularity of OLIF, several surgeons have started using larger cages to attain greater lordosis correction. Moreover, some studies have reported complications of OLIF because of immoderate cage insertion. To our knowledge, this is the first prospective study that attempted to determine whether it is possible to predict the lordosis correction angle achieved with OLIF preoperatively, using fullextension lateral view (FELV).

Methods: Forty-six patients with ASD were enrolled. All the operations were performed by a single surgeon in two stages (first, anterior and second, posterior) with a 1-week interval. Radiological evaluation was performed by comparing the Cobb's angle of the segmental and regional lordosis obtained using preoperative and postoperative simple radiography (including the FELV) and magnetic resonance imaging (MRI).

Results: Regional lordosis (L1-S1) in the whole-spine standing lateral radiograph was $-3.03^{\circ}$; however, in the supine lateral MRI, it was $20.92^{\circ}$. The regional lordosis of whole-spine standing lateral and supine lateral (MRI) was significantly different. In the FELV, regional lordosis was $25.72^{\circ}$ and that in the postoperative supine lateral (MRI) was $25.02^{\circ}$; these values were not significantly different.

Conclusions: Although OLIF offers many advantages, it alone plays a limited role in ASD treatment. Lordosis correction using OLIF as well as lordosis determined in the FELV was possible. Hence, our results suggest that FELV can help predict the lordosis correction angle preoperatively and thus aid the selection of the appropriate technique in the second staged operation.

Keywords: Oblique lumbar interbody fusion; Minimal invasive surgical procedures; Sagittal imbalance; Lordosis correction angle; Adult spinal deformity

Received Nov 29, 2018; Revised Feb 7, 2019; Accepted Mar 7, 2019

Corresponding author: Jae Won Lee

Department of Orthopedic Surgery, Eulji University Hospital, 95 Dunsanseo-ro, Seo-gu, Daejeon 35233, Korea

Tel: +82-42-611-3267, Fax: +82-42-259-1289, E-mail: fromjtothes@gmail.com 


\section{Introduction}

The incidence of adult spinal deformity (ASD) is increasing with population aging. The loss of sagittal balance is associated with pain and disability, and its restoration is the primary goal of ASD treatment. The traditional method of correcting ASD is posterior-only surgery, such as Smith-Petersen osteotomy and pedicle subtraction osteotomy (PSO). However, long-segment instrumented fusion in ASD treatment is associated with various complications, such as excessive bleeding, neurologic deficit, pseudarthrosis, deep wound infection, and junctional problems, including proximal junctional failure, screw pullout, and stenosis [1,2]. Therefore, minimally invasive (MI) fusion and instrumentation techniques are being used in ASD treatment as less invasive approaches that involve minimum complications [3]. With the increasing popularity of MI techniques [4-6], they have been developed and introduced to minimize surgical trauma and reduce bleeding and infection rates while shortening the length of hospitalization. Moreover, in large curves, structural anterior column support provides several benefits, including improved stability, decreased stress on screws, higher fusion rates, and better lumbar lordosis (LL) [7-9]. Furthermore, anterior lumbar interbody fusion (ALIF) techniques have been introduced for correcting ASD with excellent results. Other advances in access approaches include the introduction of the lateral lumbar interbody fusion (LLIF) $[10,11]$ that allows access to the lumbar spine via a lateral approach that passes through the retroperitoneal space and psoas muscle. However, $30 \%$ of the patients exhibited paresthesia, thigh pain, and lumbar plexus injury after surgery using the direct lateral approach [12]. Furthermore, there is a high prevalence of transient anterior thigh symptoms despite real-time electromyography monitoring [13]. In order to avoid nerve injury, mini-open anterior retroperitoneal lumbar interbody fusion methods, such as oblique lumbar interbody fusion (OLIF), have been recently used $[1,14,15]$. This approach accesses the spine between the anterior vessels and the psoas muscles, avoiding both the structures to allow efficient clearance of disc space and application of a large interbody device to afford distraction for foraminal decompression and endplate preparation for rapid and thorough fusion. Furthermore, the OLIF approach is considered to overcome the limitations of both, the ALIF and LLIF techniques, with the anterior approach being associ- ated with iliac vessel and peritoneal injury [16-18] and the lateral approach being associated with psoas muscle splitting and limited lower lumbar spine access $[12,13]$.

Many previous studies on the surgical treatment of ALIF, LLIF, and OLIF have shown improved clinical and radiologic outcomes. Research has shown satisfactory correction, favorable clinical and radiological results, and improved restoration of LL. However, previous studies were conducted for patients with mild sagittal imbalance, degenerative scoliosis, or spondylolisthesis. They reported about $2^{\circ}-9^{\circ} \mathrm{LL}$ correction through relative short-level fusion [3,19-22]. In some cases, the authors reported $>10^{\circ}$ correction angle because they performed anterior column release (ACR) [23-25]. Moreover, in order to treat degenerative sagittal imbalance or postoperative flat back deformity, a large lordosis correction angle and long-level fusion are necessary to restore the sagittal balance. The current trend in the operative treatment for degenerative sagittal imbalance or postoperative flat back deformity is combined anterior-posterior staged surgery. When the anterior procedure is performed first, OLIF is performed; this is the reason for the increasing popularity of OLIF. Further, with the increasing popularity of OLIF, several surgeons have started using a larger cage to achieve greater lordosis correction. Further, some studies have reported complications of OLIF because of immoderate cage insertion [26]. However, few studies have evaluated the appropriate lordosis correction angle or preoperative prediction of the possible lordosis correction angle achieved using OLIF during ASD treatment. Thus, we aimed to determine the degree of lordosis correction that can be achieved using LIOF and whether preoperative prediction of the lordosis correction angle that can be achieved using OLIF is possible. Moreover, this study can help select the appropriate second-staged posterior surgery (e.g., facetectomy, Ponte osteotomy, or PSO).

\section{Materials and Methods}

\section{Patients and methods}

The Institutional Review Board approved this study (EUH IRB file no., 2018-02-005); informed consent was obtained from all the eligible patients before they were enrolled in the study.

We performed a prospective analysis of 46 patients between April 2015 and July 2017. The study population 
Table 1. Demographic characteristics

\begin{tabular}{|cc|}
\hline Characteristic & Value \\
\hline No. of patients & 46 \\
\hline Sex (female:male) & $43: 3$ \\
\hline Age (yr) & $68.89 \pm 7$ \\
\hline Bone mineral density (T-score) & $-1.83 \pm 1$ \\
\hline Body mass index (kg/m ${ }^{2}$ ) & $25 \pm 3$ \\
\hline Diagnosis & 29 \\
\hline Degenerative sagittal imbalance & 21 \\
\hline Degenerative lumbar kyphosis & 8 \\
\hline Degenerative lumbar scoliosis & 17 \\
\hline Postoperative flat back deformity & $16.00 \pm 5.7$ \\
\hline Spinopelvic parameter & $32.5 \pm 8.9$ \\
\hline Sagittal vertical axis (cm) & $-2.47 \pm 16.2$ \\
\hline Pelvic tilt ( ${ }^{\circ}$ )
\end{tabular}

Values are presented as number or mean \pm standard deviation.

included 43 women and three men, with a mean age of 68.89 years (range, $51-77$ years). The inclusion criteria were as follows: (1) presence of degenerative sagittal imbalance, including lumbar degenerative kyphosis and degenerative lumbar scoliosis and (2) postoperative flat back deformity. Patients who had a spinal tumor, infection, ankylosing spondylitis, or acute vertebral fracture of the thoracic and lumbar spine were excluded. Patients were diagnosed using simple radiography, magnetic resonance imaging (MRI), and computed tomography. The surgical indication was determined based on the clinical symptoms and radiological parameters. The patients' demographic characteristics are shown in Table 1.

All the operations were performed by a single surgeon in two stages with a 1-week interval. During the first surgery, all the patients initially underwent OLIF surgery. The OLIF approach was from the left side in all the cases. The most proximal to the distal level of OLIF was L1-2 to L5-S1. The fusion level was decided (from 1 level to 4 levels) as per the patient's condition. Table 2 shows all the operative options. Simple radiography and MRI were obtained within a week of the first operation, and indirect neural decompression on MRI after OLIF surgery was evaluated to determine the decompression level for the second surgery. Based on the immediate postoperative LL shown on simple radiography and MRI, posterior fixation and correction methods (facetectomy, Ponte osteotomy, or
Table 2. Overall of operation options

\begin{tabular}{|cc|}
\hline Operative options & Number \\
\hline Fusion levels (OLIF) & 138 \\
\hline 1 Level & 2 \\
\hline 2 Levels & 4 \\
\hline Levels & 32 \\
\hline 4 Levels & 8 \\
\hline Fusion site (OLIF) & \\
\hline L1-2 & 7 \\
\hline L2-3 & 45 \\
\hline L3-4 & 44 \\
\hline L4-5 & 35 \\
\hline L5-S1 & 7 \\
\hline Posterior surgery & 20 \\
\hline Ponte osteotomy & 26 \\
\hline Pedicle subtraction osteotomy & \\
\hline
\end{tabular}

PSO) were determined as per the degree of LL correction required, as compared to pelvic incidence (PI) minus LL.

\section{Radiological evaluation}

All the patients underwent preoperative and postoperative simple radiography and MRI. Simple radiography comprised whole-spine standing anteroposterior/lateral (WSSA/L), supine anteroposterior/lateral, and full-extension lateral view (FELV). The WSSA/L followed the Spinal Deformity Study Group method, described as follows: (1) fists-on-clavicle position or cross-arm position for the upper extremity and (2) full-extension hip and knee joints. The FELV was taken in the trans-lateral position with the patient's back fully extended by placement of relatively hard pillows under the patient's back (Fig. 1). Radiological evaluation was performed by comparing the Cobb's angle obtained in the preoperative and postoperative simple radiography and MRI. Radiologic measurement was conducted using m-view (Infinitt Healthcare Co., Seoul, Korea) on the Hospital's Picture Archiving and Communication System. We measured both, segmental and regional lordosis. Segmental lordosis means lordosis at one level; this was measured from the inferior endplate of the upper vertebral body to the superior endplate of the lower vertebral body. Regional lordosis represents the lordosis of the lumbar spine measured from the superior endplate 

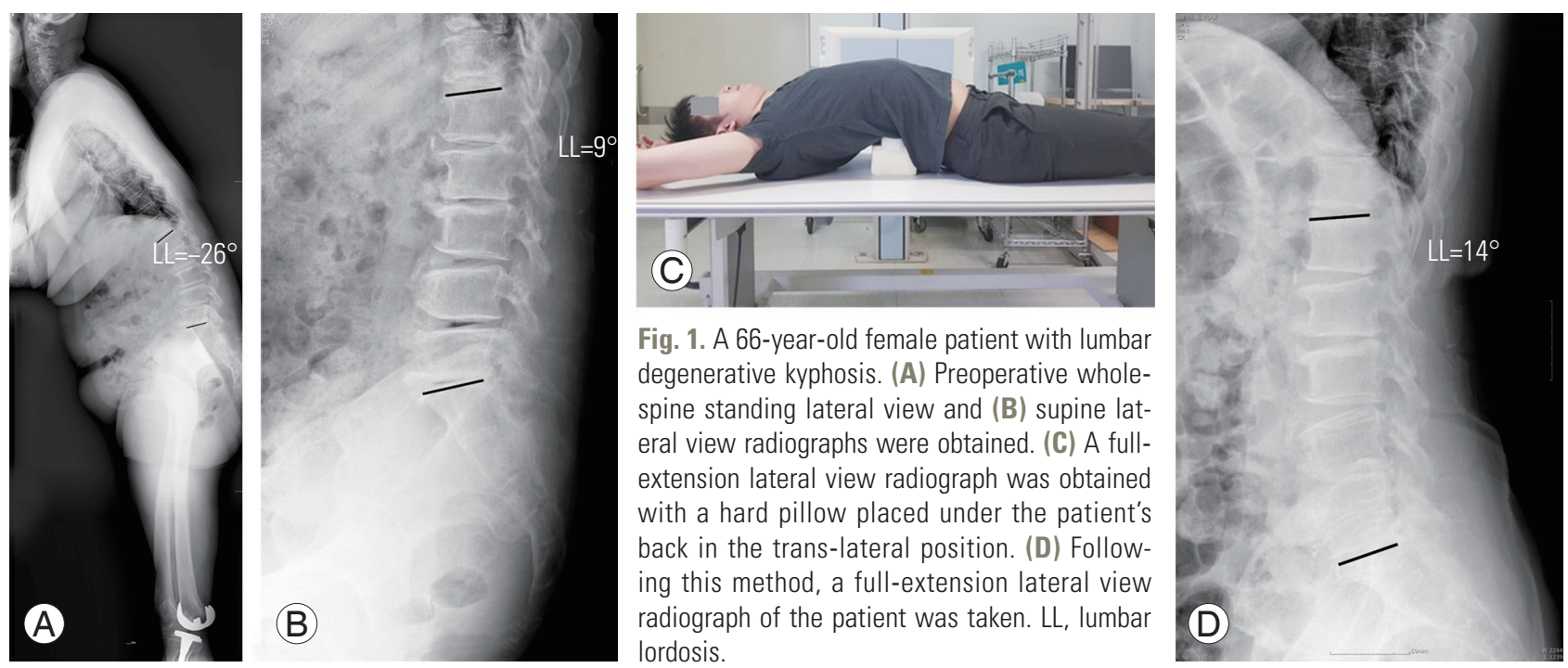

Table 3. Preoperative radiologic evaluation

\begin{tabular}{|c|c|c|c|c|}
\hline \multirow{2}{*}{ Level } & \multirow{2}{*}{$\begin{array}{c}\text { Whole spine } \\
\text { standing lateral }\end{array}$} & \multicolumn{2}{|c|}{ Supine lateral } & \multirow{2}{*}{$\begin{array}{l}\text { Full extension } \\
\text { lateral view }\end{array}$} \\
\hline & & Simple radiography & Magnetic resonance imaging & \\
\hline \multicolumn{5}{|c|}{ Segmental lordosis } \\
\hline L1-2 & $1.35 \pm 2.24$ & $5.86 \pm 2.17$ & $5.29 \pm 1.77$ & $6.04 \pm 2.94$ \\
\hline L2-3 & $3.15 \pm 3.66$ & $4.7 \pm 3.46$ & $4.63 \pm 1.76$ & $8.48 \pm 3.88$ \\
\hline L3-4 & $0.91 \pm 2.43$ & $4.63 \pm 2.23$ & $4.62 \pm 1.63$ & $6.37 \pm 3.09$ \\
\hline$\lfloor 4-5$ & $0.5 \pm 2.10$ & $5.18 \pm 1.92$ & $5.00 \pm 3.05$ & $6.62 \pm 4.39$ \\
\hline L5-S1 & $0.85 \pm 0.78$ & $2.95 \pm 1.06$ & $2.95 \pm 0.64$ & $9.70 \pm 0.42$ \\
\hline \multicolumn{5}{|c|}{ Regional lordosis } \\
\hline L1-S1 & $-3.03 \pm 13.55$ & $21.98 \pm 10.16$ & $25.72 \pm 11.49$ & $20.92 \pm 5.48$ \\
\hline
\end{tabular}

Values are presented as mean \pm standard deviation. A $p$-value $<0.05$ is statistically significant.

of the L1 vertebral body to the superior endplate of the S1 vertebral body. We also measured the disc height pre- and postoperatively. The disc height was measured between the centers of the endplate at each disc space. By comparing the pre- and postoperative disc height and used cage height, we want to verify that measuring the preoperative disc height matches the actual used cage and how cage height affects the change of disc height.

\section{Statistical analysis}

Differences between the preoperative and postoperative variables were assessed using a paired Student $t$-test. Statistical analyses were performed using IBM SPSS ver. 22.0 software (IBM Corp., Armonk, NY, USA). A p-value $<0.05$ was considered statistically significant.

\section{Results}

\section{Preoperative radiologic evaluation}

The results of the preoperative radiologic evaluation are shown in Table 3. Segmental and regional lordosis was measured. We measured lordosis at SL using simple radiography and MRI. Technically, bony distinction and measurement repeatability were better in the MRI. Hence, we used the values obtained using MRI when we compared the lordosis statistically.

In WSSL, kyphotic changes were observed at the lumbar levels. The mean segmental lordosis in WSSL was $1.35^{\circ}$; however, that in SL (MRI) was $4.49^{\circ}$. A statistical significance was found between each WSSL segmental lordosis as well as mean segmental lordosis and those in SL (MRI). 
Table 4. Comparison of preoperative radiologic parameters

\begin{tabular}{|c|c|c|c|}
\hline Level & Whole spine standing lateral & Supine lateral (magnetic resonance imaging) & $p$-value \\
\hline \multicolumn{4}{|c|}{ Segmental lordosis } \\
\hline $\mathrm{L} 1-2$ & $1.35 \pm 2.24$ & $5.29 \pm 1.77$ & $0.024^{*}$ \\
\hline L2-3 & $3.15 \pm 3.66$ & $4.63 \pm 1.76$ & $0.048^{*}$ \\
\hline L3-4 & $0.91 \pm 2.43$ & $4.62 \pm 1.63$ & $0.017^{*}$ \\
\hline$\llcorner 4-5$ & $0.5 \pm 2.10$ & $5.00 \pm 3.05$ & $0.031^{*}$ \\
\hline L5-S1 & $0.85 \pm 0.78$ & $2.95 \pm 0.64$ & $0.044^{*}$ \\
\hline Mean & $1.35 \pm 2.24$ & $4.49 \pm 1.77$ & $0.029^{*}$ \\
\hline \multicolumn{4}{|c|}{ Regional lordosis } \\
\hline L1-S1 & $-3.03 \pm 13.55$ & $20.92 \pm 5.48$ & $<0.001^{*}$ \\
\hline
\end{tabular}

Values are presented as mean \pm standard deviation.

${ }^{*} p<0.05$ indicates statistical significance.

Table 5. Comparison of postoperative radiologic parameters

\begin{tabular}{lccc} 
Level & Full extension lateral view & Postoperative supine lateral (magnetic resonance imaging) & $p$-value \\
Segmental lordosis & & & $5.93 \pm 3.14$ \\
\hline L1-2 & $6.04 \pm 2.94$ & $8.43 \pm 3.85$ & 0.589 \\
\hline L2-3 & $8.48 \pm 3.88$ & $6.32 \pm 3.31$ & 0.551 \\
\hline L3-4 & $6.37 \pm 3.09$ & $6.84 \pm 3.07$ & 0.613 \\
\hline L4-5 & $6.62 \pm 4.39$ & $9.75 \pm 2.33$ & 0.601 \\
\hline L5-S1 & $9.70 \pm 0.42$ & $7.45 \pm 3.12$ & 0.612 \\
\hline Mean & $7.44 \pm 2.92$ & & 0.683 \\
\hline Regional lordosis & & $25.02 \pm 7.09$ & 0.832 \\
\hline L1-S1 & $25.72 \pm 11.49$ & & \\
\hline
\end{tabular}

Values are presented as mean \pm standard deviation. A $p$-value $<0.05$ is statistically significant.

Moreover, the regional lordosis in WSSL was $-3.03^{\circ}$; however, that in SL (MRI) was $20.92^{\circ}$. A significant difference was found between the regional lordosis of WSSL and that in SL (MRI) (Table 4, Fig. 2).

\section{Postoperative radiologic evaluation}

Results of the postoperative radiologic evaluation are shown in Table 5. The mean segmental lordosis at FELV was $7.44^{\circ}$, and the mean postoperative segmental lordosis at SL (MRI) was $7.45^{\circ}$. The regional lordosis was $25.72^{\circ}$ and $25.02^{\circ}$ at FELV and postoperative SL (MRI), respectively (Fig. 3). The segmental or regional lordosis were not significantly different (Fig. 4).

\section{Disc height comparison}

The comparison between preoperative and postoperative

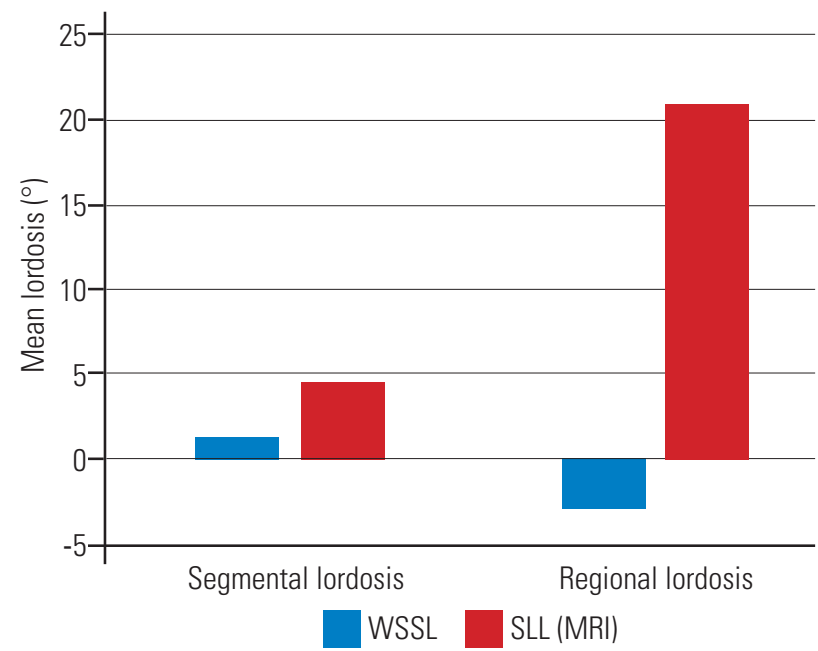

Fig. 2. The mean segmental lordosis and mean regional lordosis were measured in the WSSL view and the SL view (MRI); the lordosis measurements were significantly different. WSSL, whole-spine standing lateral; SL, supine lateral; MRI, magnetic resonance imaging. 
disc height has been shown in Table 6. No significant difference was found between the disc height in the FELV and postoperative SL (MRI) at each level. At L4-5 and L5-S1, the cage used matched the height of the FELV; however, the cages used in L1-2, L2-3, and L3-4 were bigger than the pre-measured disc height for each level (Table 7). Thus, using a bigger cage did not increase the disc height (Fig. 5).

\section{Discussion}

With the growing elderly population, the incidence of ASD has also increased. Restoration of sagittal balance is the goal of ASD treatment. Recently, operative treatments of ASD have increased because of the growing demand for

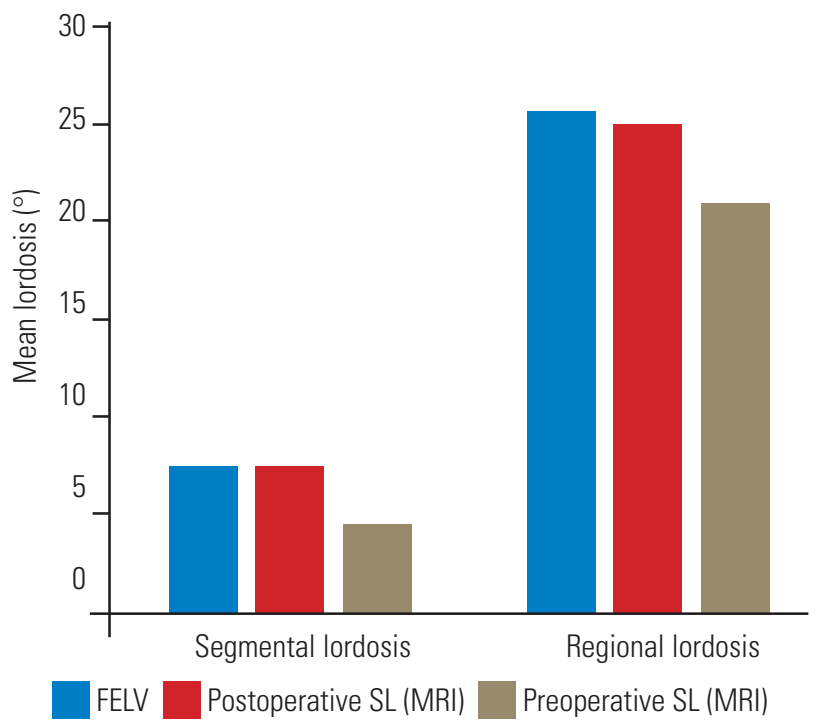

Fig. 3. The mean segmental lordosis and mean regional lordosis in the FELV were compared with those in the postoperative SL view (MRI) and the preoperative SL view. No significant differences were found between the lordosis in the FELV and the postoperative SL view (MRI). FELV, full-extension lateral view; SL, supine lateral; MRI, magnetic resonance imaging enhanced quality of life and improved surgical techniques. However, the conventional open approach, PSO, showed a high complication rate of up to 78\% [27]; the complications include massive bleeding, neurologic deficits, and pseudarthrosis. Through efforts to avoid tree column osteotomy (PSO) and restore sagittal balance with fewer surgical complications, many surgeons have performed the combined anterior-posterior staged surgery [28,29]. Furthermore, MI surgery techniques have improved [3,79], and the anterior procedure has been used for ASD treatment. Many studies have reported good results with satisfactory restoration of LL using lumbar interbody fusion, such as ALIF, DLIF, or OLIF. However, these studies were conducted in patients with a relatively mild deformity. Therefore, studies on the clinical results of long-level fusion for more lordosis correction are limited. Moreover,
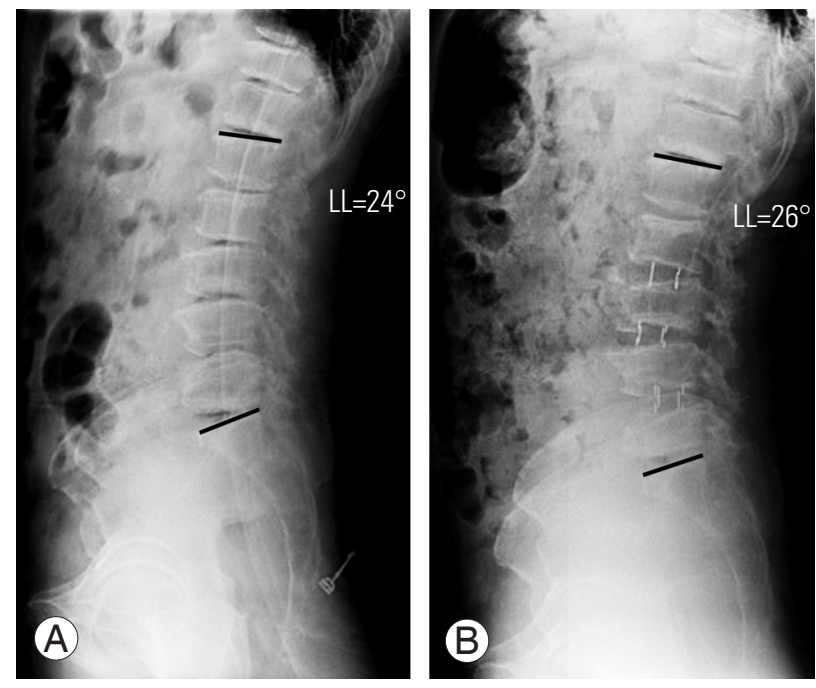

Fig. 4. A 71-year-old female patient with lumbar degenerative kyphosis. (A) Preoperative full-extension lateral view and (B) postoperative supine lateral view radiographs were taken. Lordosis in the preoperative full-extension lateral view and in the postoperative supine lateral view were not significantly different. LL, lumbar lordosis.

Table 6. Disc height comparison

\begin{tabular}{lccc} 
Level & Full extension lateral view & Postoperative supine lateral (magnetic resonance imaging) & $p$-value \\
L1-2 & $9.93 \pm 1.93$ & $9.76 \pm 2.01$ & 0.108 \\
L2-3 & $10.16 \pm 1.75$ & $10.21 \pm 0.84$ & 0.791 \\
L3-4 & $10.19 \pm 2.26$ & $10.42 \pm 2.44$ & 0.713 \\
L4-5 & $11.49 \pm 2.46$ & $11.20 \pm 10.1$ & 0.696 \\
L5-S1 & $10.29 \pm 3.71$ & $10.05 \pm 3.74$ & 0.601 \\
\hline
\end{tabular}

Values are presented as mean \pm standard deviation. A $p$-value $<0.05$ is statistically significant. 
only few recent studies have assessed the perioperative complications of OLIF because of improper cage usage [26]. In order to achieve more lordosis correction without cage-related complications, some studies have suggested ACR as an alternative method [30]. However, ACR is a technically demanding procedure with complications (19\%) [31] that exceeds the usual MI concept. Thus, the degree of lordosis correction that can be achieved with OLIF and the method of planning of the second posterior surgery by surgeons are important issues in ASD treat-

Table 7. Used cages

\begin{tabular}{lcc} 
Level & Full extension lateral view & Used cage \\
\hline L1-2 & $9.93 \pm 1.93$ & $11.00 \pm 1.74$ \\
L2-3 & $10.16 \pm 1.75$ & $11.50 \pm 1.00$ \\
L3-4 & $10.19 \pm 2.26$ & $11.33 \pm 2.06$ \\
L4-5 & $11.49 \pm 2.46$ & $11.20 \pm 1.09$ \\
\hline L5-S1 & $10.29 \pm 3.71$ & $10.00 \pm 2.82$ \\
\hline
\end{tabular}

Values are presented as mean \pm standard deviation. ment.

In this study, preoperative radiologic evaluation revealed a significant difference in lordosis at WSSL and SL (MRI), indicating positional restoration of lordosis (Fig. 6). Thus, a misunderstanding can occur, depending on the position used. There is no standard basis of valuation; thus, surgeons may interpret that more lordosis correction was achieved, depending on the valuation (Fig. 7). Furthermore, the flexibility of the deformity can affect the correction angle after OLIF. Comparing the lordosis change in WSSL and SL (MRI) preoperatively to predict the flexibility of the deformity will be helpful. Therefore, when evaluating lordosis correction, surgeons should not focus on the degree of correction, but on the required degree of correction, as compared with PI minus LL $\left(< \pm 10^{\circ}\right)$.

We designed the FELV to predict the lordosis correction angle that can be achieved using OLIF (Fig. 1C). We hypothesized that the lordosis correction using OLIF would depend on the lordosis angle in the FELV. We assumed that OLIF is only applicable for limited correction because it is preserved in the anterior longitudinal ligament (ALL).

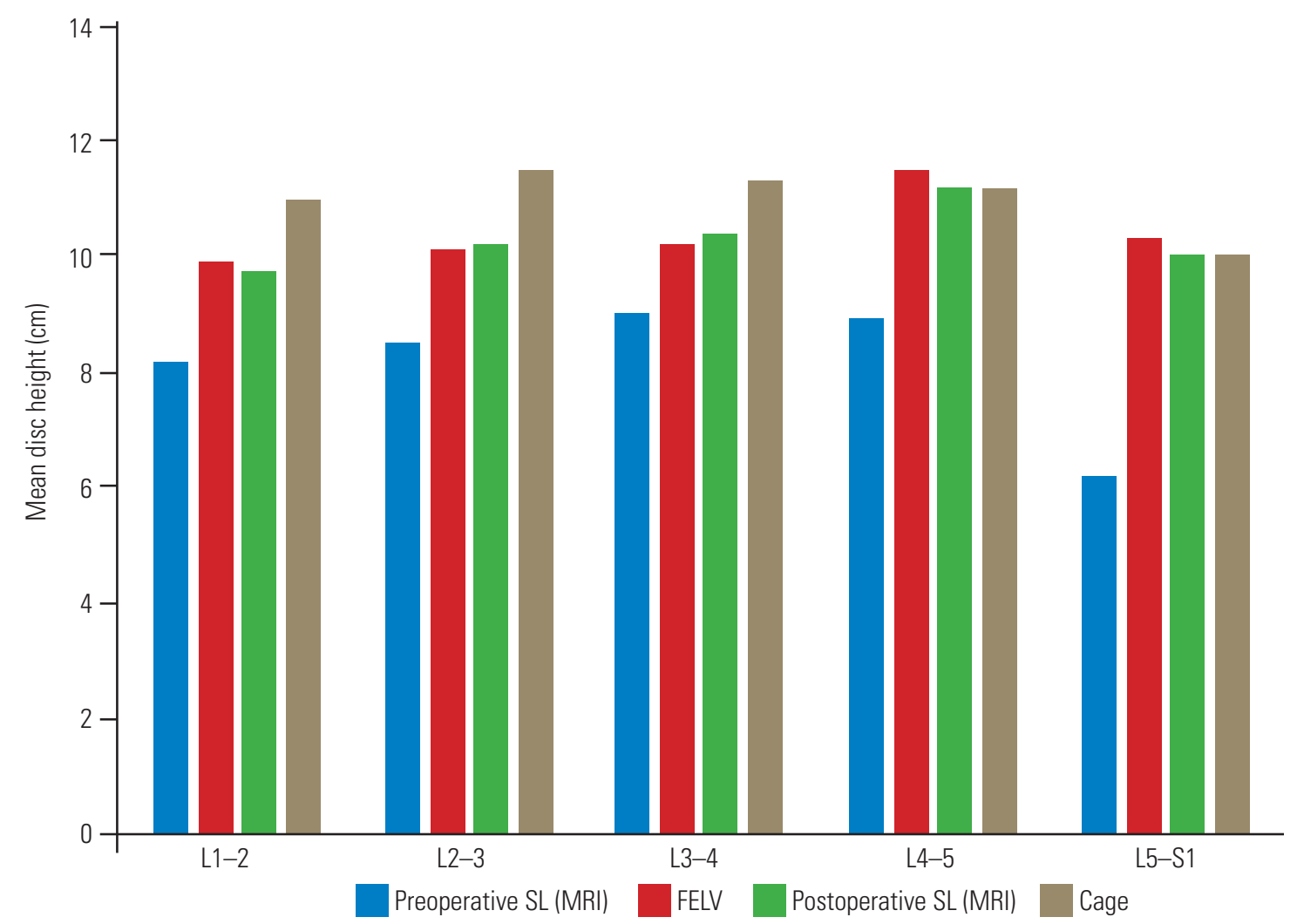

Fig. 5. The mean disc height of each level in the FELV was compared with that in the preoperative SL view, postoperative SL view (MRI), and height of the cage used. The disc height in the FELV and postoperative SL view (MRI) showed no significant difference. Furthermore, using a larger cage did not affect the increase in disc height. FELV, full-extension lateral view; SL, supine lateral; MRI, magnetic resonance imaging. 
In particular, OLIF would have a limited role in relatively rigid ASD because of facet joint arthrosis, osteophytes, and adhesion. Based on the results of postoperative radiologic evaluation, we verified that the degree of lordosis measured in postoperative SL (MRI) and FELV was not
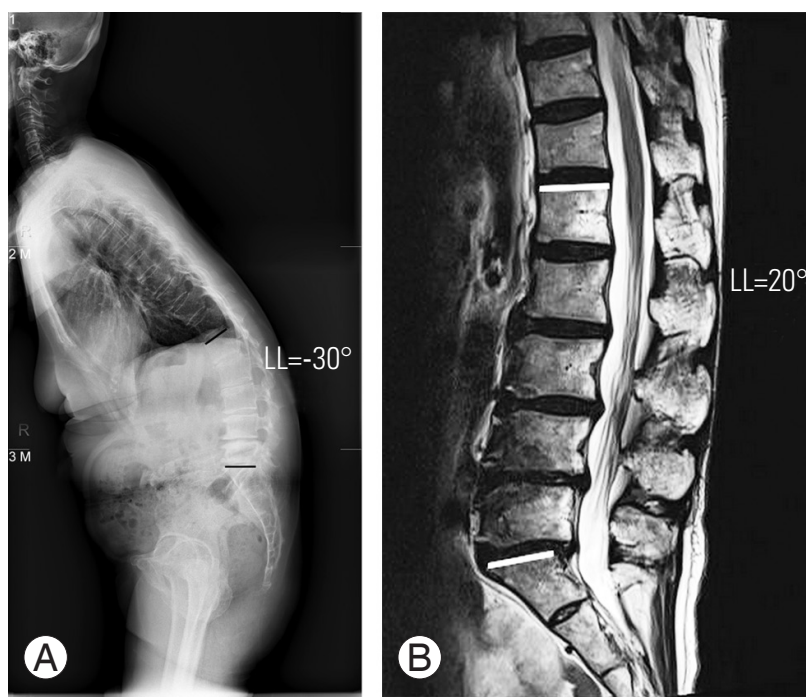

Fig. 6. A 63-year-old female patient with lumbar degenerative kyphosis. (A) The patient shows kyphotic curvature $\left(\mathrm{LL}=-30^{\circ}\right)$ in preoperative whole-spine standing lateral radiograph. (B) However, at the preoperative supine view (magnetic resonance imaging), the curvature changes to lordosis $\left(\mathrm{LL}=20^{\circ}\right)$. It shows the positional restoration of lordosis. LL, lumbar lordosis. significantly different. As expected, the lordosis correction angle achieved using OLIF is similar to the lordosis mea-
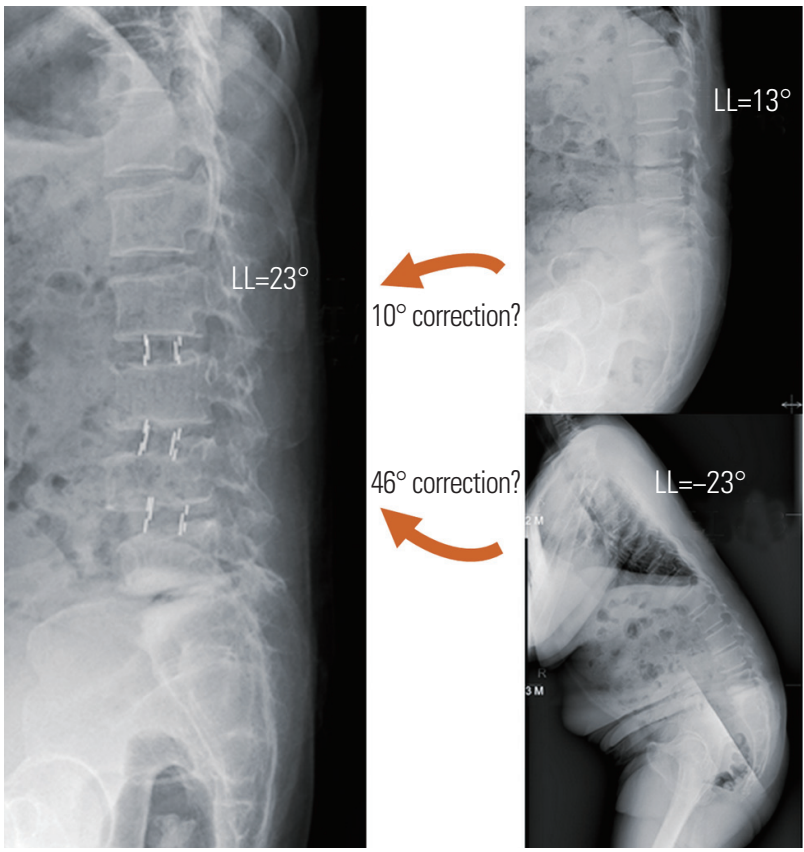

Fig. 7. A 23-year-old female patient with lumbar degenerative kyphosis. Lordosis in the preoperative whole-spine standing lateral radiograph was $-23^{\circ}$ (kyphosis), and lordosis in the SL position was $13^{\circ}$. After OLIF, Iordosis in the postoperative SL position was $23^{\circ}$. Lordosis correction angle achieved using OLIF was $10^{\circ}$ from $13^{\circ}$ (SL) or $46^{\circ}$ from $-23^{\circ}$ (whole-spine standing lateral). OLIF, oblique lumbar interbody fusion; LL, lumbar lordosis; SL, supine lateral.
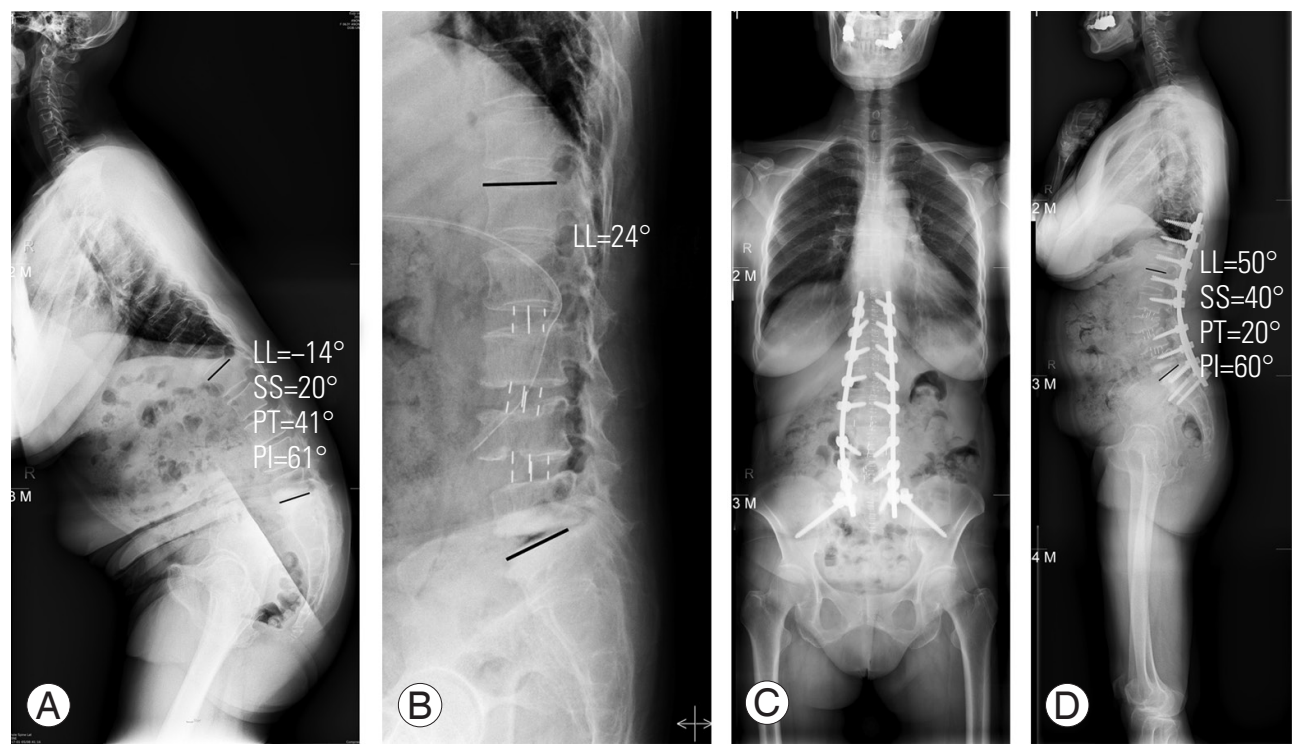

Fig. 8. A 64-year-old female patient with lumbar degenerative kyphosis. (A) In preoperative whole-spine standing lateral position, the LL was $-14^{\circ}$ (kyphosis). (B) After oblique lumbar interbody fusion (L2-3, L3-4, L4-5), the $\mathrm{LL}$ was corrected to $24^{\circ}$, in the postoperative supine lateral position. Considering the pelvic incidence minus $\mathrm{LL}$, the required additional lordosis correction angle was about $30^{\circ}$. Hence, we performed pedicle subtraction osteotomy at L3 after 1 week. (C) Postoperative whole-spine standing anteroposterior and (D) lateral were taken 2 weeks after the second staged operation. LL, lumbar lordosis; SS, sacral slope; PT, pelvic tilt; PI, pelvic incidence. 
sured in the FELV. Thus, lordosis correction using OLIF would have a limited role in ASD treatment, and lordosis in the FELV could predict the correction angle after OLIF. If the surgeon corrects lordosis through the OLIF technique alone, there is a risk of under-correction. In order to attain sufficient lordosis correction using OLIF without additional posterior procedure (facetectomy, Ponte, or PSO), the ALL should be released. Thus, surgeons can predict the lordosis correction angle using the FELV and can plan a secondary operation, if necessary. If the required additional lordosis correction angle is $>30^{\circ}$ after OLIF as the first-staged operation, considering PI minus LL $\left(< \pm 10^{\circ}\right)$, PSO would be needed (Fig. 8). Immoderate cage insertion to obtain more lordosis correction would be ineffective and could cause perioperative complications.

We also evaluated the disc height and the cage used. The disc heights at each level in the FELV were similar to those in postoperative SL (MRI) (no significant difference). However, the cages used did not fully match with the disc height in the FELV. When the surgeons choose the cage, they should consider not only the premeasured disc height, but also the instruments used during the operation. If a larger cage size can fit in, many surgeons tend to choose larger ones for more lordosis correction. However, during procedure preparation, endplate damage occurs easily because of osteoporotic, poor bone quality. In our case, L4-5 and L5-S1 almost matched FELV, postoperative SL (MRI), and used cages. In L1-2, L2-3, and L3-4, we used larger-sized cages than those in the FELV; however, the disc height of the postoperative SL (MRI) was not significantly different from that with the FELV. Thus, a larger-sized cage was unable to achieve greater lordosis correction or disc height. Therefore, it is unnecessary to use a larger-sized cage for correction.

\section{Conclusions}

OLIF is the preferred surgical method for ASD treatment because it offers many mechanical benefits, including improved stability, decreased stress on screws, higher fusion rates, and better LL. Moreover, it can minimize complications, such as surgical trauma, reduced bleeding, and infection rates while shortening the length of hospitalization. Despite these advantages, OLIF alone is insufficient to restore the sagittal balance considering the PI minus LL $\left(< \pm 10^{\circ}\right)$. Lordosis correction using OLIF was possible as much as the lordosis in the FELV. Thus, our results suggest that FELV can help predict the lordosis correction angle preoperatively and plan a proper second staged operation. An impractical correction goal and insertion of an immoderate cage are not recommended. Considering the FELV preoperatively can be an acceptable and effective strategy that can help in setting an appropriate correction plan, including osteotomy, if necessary, to achieve a greater lordosis correction angle.

\section{Conflict of Interest}

No potential conflict of interest relevant to this article was reported.

\section{ORCID}

Jae Won Lee: https://orcid.org/0000-0001-6632-2609

\section{References}

1. Ohtori S, Orita S, Yamauchi K, et al. Mini-open anterior retroperitoneal lumbar interbody fusion: oblique lateral interbody fusion for lumbar spinal degeneration disease. Yonsei Med J 2015;56:1051-9.

2. Schwab F, Ungar B, Blondel B, et al. Scoliosis Research Society-Schwab adult spinal deformity classification: a validation study. Spine (Phila Pa 1976) 2012;37:1077-82.

3. Manwaring JC, Bach K, Ahmadian AA, Deukmedjian AR, Smith DA, Uribe JS. Management of sagittal balance in adult spinal deformity with minimally invasive anterolateral lumbar interbody fusion: a preliminary radiographic study. J Neurosurg Spine 2014;20:515-22.

4. Anand N, Rosemann R, Khalsa B, Baron EM. Midterm to long-term clinical and functional outcomes of minimally invasive correction and fusion for adults with scoliosis. Neurosurg Focus 2010;28:E6.

5. Carreon LY, Puno RM, Dimar JR 2nd, Glassman SD, Johnson JR. Perioperative complications of posterior lumbar decompression and arthrodesis in older adults. J Bone Joint Surg Am 2003;85:2089-92.

6. Tormenti MJ, Maserati MB, Bonfield CM, Okonkwo DO, Kanter AS. Complications and radiographic correction in adult scoliosis following combined transpsoas extreme lateral interbody fusion and posterior 
pedicle screw instrumentation. Neurosurg Focus 2010;28:E7.

7. Hsieh PC, Koski TR, O'Shaughnessy BA, et al. Anterior lumbar interbody fusion in comparison with transforaminal lumbar interbody fusion: implications for the restoration of foraminal height, local disc angle, lumbar lordosis, and sagittal balance. J Neurosurg Spine 2007;7:379-86.

8. Niemeyer TK, Koriller M, Claes L, Kettler A, Werner K, Wilke HJ. In vitro study of biomechanical behavior of anterior and transforaminal lumbar interbody instrumentation techniques. Neurosurgery 2006;59:1271-6.

9. Ploumis A, Wu C, Fischer G, et al. Biomechanical comparison of anterior lumbar interbody fusion and transforaminal lumbar interbody fusion. J Spinal Disord Tech 2008;21:120-5.

10. Ozgur BM, Aryan HE, Pimenta L, Taylor WR. Extreme lateral interbody fusion (XLIF): a novel surgical technique for anterior lumbar interbody fusion. Spine J 2006;6:435-43.

11. Arnold PM, Anderson KK, McGuire RA Jr. The lateral transpsoas approach to the lumbar and thoracic spine: a review. Surg Neurol Int 2012;3(Suppl 3):S198-215.

12. Bergey DL, Villavicencio AT, Goldstein T, Regan JJ. Endoscopic lateral transpsoas approach to the lumbar spine. Spine (Phila Pa 1976) 2004;29:1681-8.

13. Cummock MD, Vanni S, Levi AD, Yu Y, Wang MY. An analysis of postoperative thigh symptoms after minimally invasive transpsoas lumbar interbody fusion. J Neurosurg Spine 2011;15:11-8.

14. Silvestre C, Mac-Thiong JM, Hilmi R, Roussouly P. Complications and morbidities of mini-open anterior retroperitoneal lumbar interbody fusion: oblique lumbar interbody fusion in 179 patients. Asian Spine J 2012;6:89-97.

15. Kanno K, Ohtori S, Orita S, et al. Miniopen oblique lateral L5-S1 interbody fusion: a report of 2 cases. Case Rep Orthop 2014;2014:603531.

16. Phan K, Thayaparan GK, Mobbs RJ. Anterior lumbar interbody fusion versus transforaminal lumbar interbody fusion: systematic review and meta-analysis. $\mathrm{Br}$ J Neurosurg 2015;29:705-11.

17. Rao PJ, Ghent F, Phan K, Lee K, Reddy R, Mobbs RJ. Stand-alone anterior lumbar interbody fusion for treatment of degenerative spondylolisthesis. J Clin
Neurosci 2015;22:1619-24.

18. Rao PJ, Loganathan A, Yeung V, Mobbs RJ. Outcomes of anterior lumbar interbody fusion surgery based on indication: a prospective study. Neurosurgery 2015;76:7-23.

19. Castro C, Oliveira L, Amaral R, Marchi L, Pimenta L. Is the lateral transpsoas approach feasible for the treatment of adult degenerative scoliosis? Clin Orthop Relat Res 2014;472:1776-83.

20. Phillips FM, Isaacs RE, Rodgers WB, et al. Adult degenerative scoliosis treated with XLIF: clinical and radiographical results of a prospective multicenter study with 24-month follow-up. Spine (Phila Pa 1976) 2013;38:1853-61.

21. Baghdadi YM, Larson AN, Dekutoski MB, et al. Sagittal balance and spinopelvic parameters after lateral lumbar interbody fusion for degenerative scoliosis: a case-control study. Spine (Phila Pa 1976) 2014;39:E166-73.

22. Acosta FL, Liu J, Slimack N, Moller D, Fessler R, Koski T. Changes in coronal and sagittal plane alignment following minimally invasive direct lateral interbody fusion for the treatment of degenerative lumbar disease in adults: a radiographic study. J Neurosurg Spine 2011;15:92-6.

23. Uribe JS, Harris JE, Beckman JM, Turner AW, Mundis GM, Akbarnia BA. Finite element analysis of lordosis restoration with anterior longitudinal ligament release and lateral hyperlordotic cage placement. Eur Spine J 2015;24 Suppl 3:420-6.

24. Berjano P, Cecchinato R, Sinigaglia A, et al. Anterior column realignment from a lateral approach for the treatment of severe sagittal imbalance: a retrospective radiographic study. Eur Spine J 2015;24 Suppl 3:4338.

25. Akbarnia BA, Mundis GM Jr, Moazzaz P, et al. Anterior column realignment (ACR) for focal kyphotic spinal deformity using a lateral transpsoas approach and ALL release. J Spinal Disord Tech 2014;27:29-39.

26. Abe K, Orita S, Mannoji C, et al. Perioperative complications in 155 patients who underwent oblique lateral interbody fusion surgery: perspectives and indications from a retrospective, multicenter survey. Spine (Phila Pa 1976) 2017;42:55-62.

27. Smith JS, Shaffrey CI, Klineberg E, et al. Complication rates associated with 3-column osteotomy in 82 adult spinal deformity patients: retrospective review 
of a prospectively collected multicenter consecutive series with 2-year follow-up. J Neurosurg Spine 2017;27:444-57.

28. Anand N, Kong C, Fessler RG. A staged protocol for circumferential minimally invasive surgical correction of adult spinal deformity. Neurosurgery 2017;81:733-9.

29. Strom RG, Bae J, Mizutani J, Valone F 3rd, Ames CP, Deviren V. Lateral interbody fusion combined with open posterior surgery for adult spinal deformity. J Neurosurg Spine 2016;25:697-705.
30. Turner JD, Akbarnia BA, Eastlack RK, et al. Radiographic outcomes of anterior column realignment for adult sagittal plane deformity: a multicenter analysis. Eur Spine J 2015;24 Suppl 3:427-32.

31. Murray G, Beckman J, Bach K, Smith DA, Dakwar E, Uribe JS. Complications and neurological deficits following minimally invasive anterior column release for adult spinal deformity: a retrospective study. Eur Spine J 2015;24 Suppl 3:397-404. 